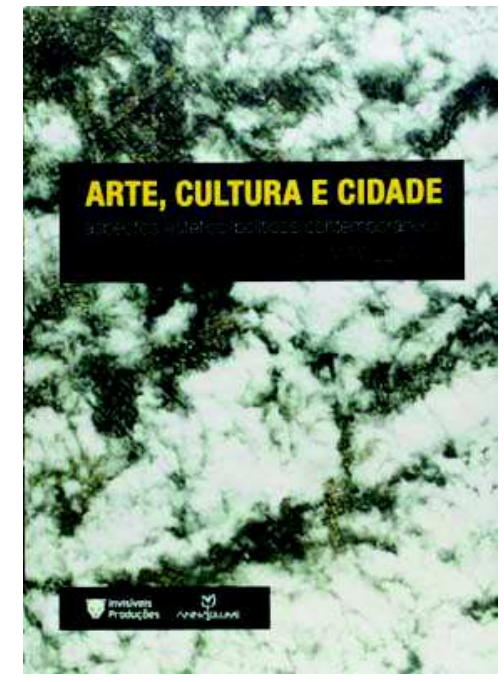

Arte, cultura e

CIDADE: ASPECTOS

ESTÉTICO-POLÍTICOS

CONTEMPORÂNEOS.

Pallamin, Vera. São Paulo:

Editora AnNablume, 2015, I99P.

Paolo Colosso

\title{
A produÇÃo de CUlTuRa URBana: PRÁTICAS ESPACIAIS E IMAGINÁRIOS EM DISPUTA
}

Em Arte, Cultura e Cidade: aspectos estético-políticos contemporâneos, a arquiteta e filósofa Vera Pallamin analisa as condições socioespaciais contemporâneas e, de modo mais detido, práticas estético-políticas cujas linhas de força não são mais, unicamente, aquelas do esvaziamento e desencantamento pós-moderno, muito bem caracterizadas por Fredric Jameson e David Harvey nos anos de 1990. Como reconhece Pallamin, lembrando Celso Favaretto, o contemporâneo não coincide com o pós-moderno, mas é um campo de indeterminação para o qual ainda não dispomos de uma linguagem capaz de traduzir suficientemente. Os autores mobilizados no livro lançado no final do ano de 2015 vêm justamente contribuir com os esforços de compreender e transformar tal realidade. 0 fio condutor que perpassa a obra de Pallamin reside nas práticas que combinam resistência e inventividade e, neste sentido, colocam-se como proposições, respostas ou intervenções no espaço urbano.

No primeiro bloco, a autora reconstitui de maneira cuidadosa os trabalhos de Jacques Rancière, cujo pensamento desloca os termos da relação entre o estético e o político e, com isso, reorganiza, ampliando, estes campos disciplinares. Como lembra Pallamin, o filósofo francês resgata uma "estética primeira" que, tendo como referência o termo grego aisthesis, reflete sobre toda a materialidade dada pela sensibilidade e partilhada histórica e socialmente. Isto é, os espaços, os tempos e atividades que moldam a maneira como o sensível é vivido pelos agentes sociais. E a partir desta acepção se deve compreender o conceito fundamental de "partilha do sensível", o qual reforça a ambiguidade de este solo compartilhado ser, por um lado, um comum por excelência e, por outro, recortado em parcelas desiguais por indivíduos que, 


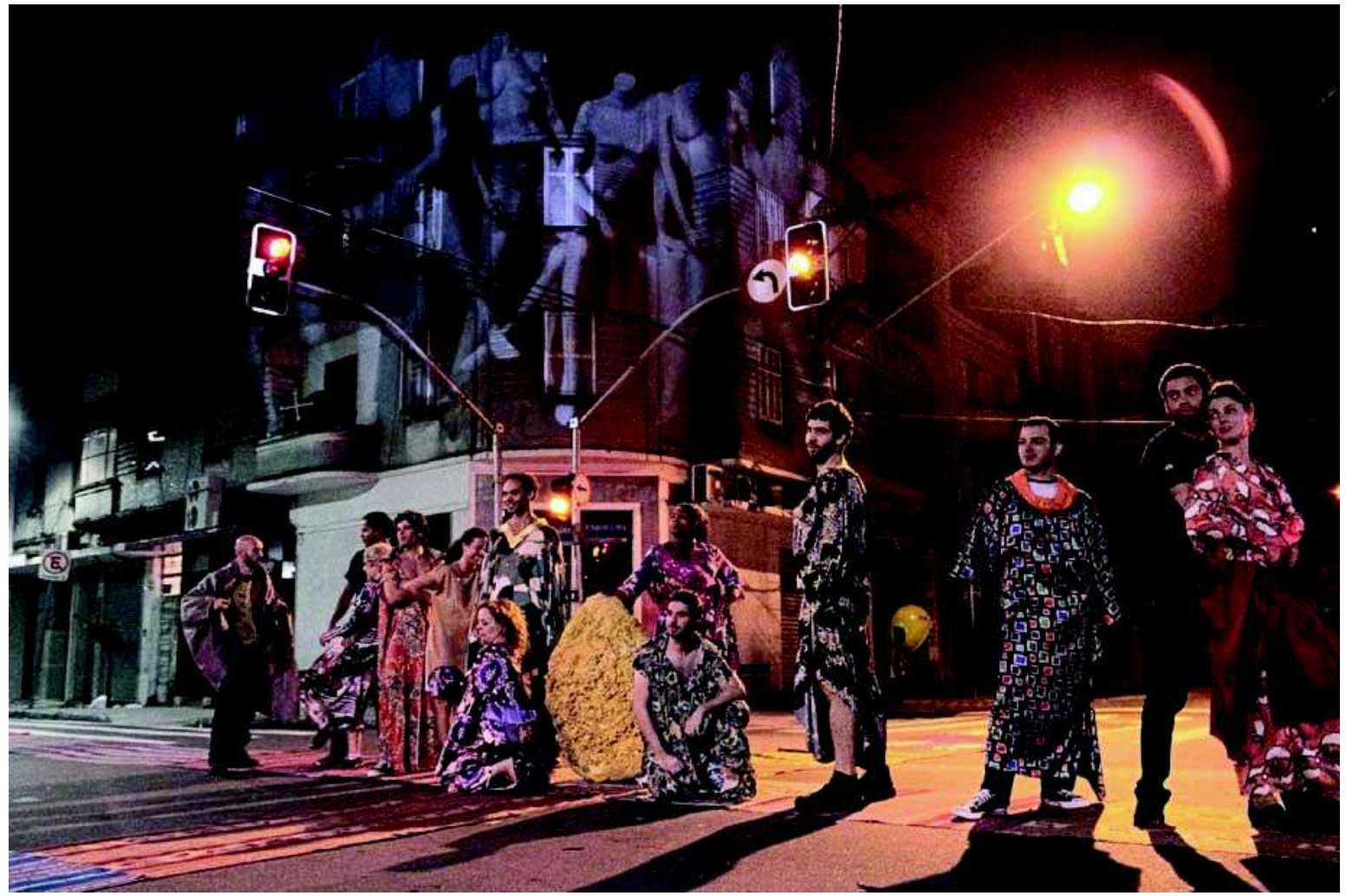

Imagem: Flávio Morbach Portella

por princípio, são iguais. O sensível encontra-se, portanto, em regime de disputa, implica divisão das ocupações e competências, diferenciações nas subjetividades, disparidades entre os que gozam de lugar de fala e outros invisibilizados, não-contados, cujas vozes são tidas como como ruídos.

Nesta linha, salienta Pallamin, a partilha do sensível diz respeito ao estético e ao político. A fundação do político se dá quando a lógica promovida pelas partilhas desiguais ou a ordem da dominação é perfurada por conflitos pautados pela atualização do princípio de igualdade. As práticas estéticas são, por sua vez, maneiras de fazer e dar visibilidade que intervêm nessa distribuição que é também simbólica. Estes são, não raro, momentos de "dissenso", nos quais as posições e os termos antes aceitos e naturalizados são postos em xeque no espaço público, seja por meio de poéticas, seja por proposições ou por suas infinitas combinações. As ações dissensuais trazem de volta uma categoria fundamental da filosofia moderna, qual seja, a da emancipação, agora entendida não tanto como fim último de um projeto politico ou um estado social reconciliado, mas como a verificação precária e persistente deste princípio de igualdade.

Da acepção da "estética" ligada ao sensível - o comum partilhado e clivado -, Rancière desdobra uma outra, que se refere à relação histórica entre modos de pensamento/percepção e a experiência social com as artes. Entre o fim do século XVIII e início do XIX, a partir das contribuições de Friedrich Schiller, mas também com a destruição das hierarquias entre os gêneros artísticos, abrese o que Rancière vai denominar "regime estético" das artes. Trata-se do 
momento em que as artes se desobrigam de uma função ética na comunidade e da representação do mundo, tornando-se uma instância específica da vida social. Ao mesmo tempo, incorporam-se às artes campos do sensível antes exteriores a ela, como o banal, o vulgar e o anônimo. Neste regime as artes mobilizam o livre jogo entre as faculdades, entre os fazeres e, ainda, fornecem aos homens, pela potência da palavra, as condições de estes se desviarem de seus destinos naturais. Em outros termos, é o momento em que o potencial performativo da palavra dita abre aos homens a possibilidade de forjarem seus próprios destinos, reconfigurando a partilha do sensível - aí está outra via de aproximação entre este regime estético e o campo do político.

Este regime estético das artes se caracteriza, sublinha Pallamin, pela tensão entre arte e vida. Isto explica a tese de O Mal-Estar na Estética [Malaise dans L'Esthétique] segundo a qual, neste período, a arte é arte, todavia é também outra coisa que não arte; uma contradição que se manifesta e se desdobra em obra, sem cessar. Não porque o fazer artístico é tido como atividade autônoma, como pensou o modernismo, mas sobretudo pois a experiência estética goza de um estatuto distintivo - como em Schiller. Contudo, a realização da promessa emancipatória da arte é, também, sua própria supressão como realidade separada da vida.

No segundo capítulo, Pallamin reconstitui alguns dos mais pertinentes debates das ultimas gerações da Teoria Crítica da Sociedade, acerca das resistências e Iutas sociais na esfera pública. A contribuição central de Pallamin é conferir a estes debates contornos mais concretos, uma vez que a autora os compreende em suas inscrições no espaço urbano. Certamente, abre-se um campo de pesquisa com possibilidades de desdobramentos fecundos.

A partir de Jürgen Habermas, mas não somente com este, ficou claro que determinados marxismos, ao compreenderem as contradições sociais unicamente como conflitos de classe, passaram ao largo de outras formas de espoliação que não aquelas circunscritas à exploração no mundo do trabalho. Isto implica, entre outras, que nem todas as demandas sociais têm motivações econômicas. Foi também Habermas que, diante da questão acerca do estabelecimento de normas justas, afasta-se do paradigma pensado para sujeitos abstratos que avaliam internamente suas condutas, como no modelo kantiano, e desloca a construção da justiça para o domínio intersubjetivo, aquele dos embates propositivos com pretensão de validade geral, os debates públicos em vista de níveis superiores de entendimento mútuo. Os trabalhos de Axel Honneth, por sua vez, assumem em larga medida os avanços propostos por Habermas, mas trazem para o centro de seu programa filosófico a categoria de reconhecimento. Aposta-se que, com esta, pode-se suprir um déficit sociológico no arcabouço habermasiano, compreendendo de maneira mais concreta tanto a formação dos sujeitos quanto a gramática das lutas sociais. Neste sentido, Honneth certamente tem contribuído para lançar luz sobre as demandas de populações historicamente invisibilizadas, estigmatizadas e privadas de acessos - mulheres, imigrantes, afrodescendentes. Entretanto, um apontamento foi feito mais recentemente: o paradigma do reconhecimento, em grande parte usado para as políticas identitárias, tem ganhado predominância justamente no período de desmanche do Welfare State e, de modo mais geral, de encolhimento de políticas redistributivas. 
Esta questão, mobilizada pela filósofa Nancy Fraser, pretende enfatizar que as lutas por justiça redistributiva não podem ser subsumidas àquelas por reconhecimento. É preciso, pelo menos em termos metodológicos, uma concepção bidimensional de justiça. Por isto a ideia de um "dualismo perspectivo". Todavia, a saída de Fraser não é deslocar-se entre um princípio e outro. Para a autora, o idioma dos embates públicos por justiça tem de ser entendido em termos de luta por "paridade de participação". Este é um critério suficientemente político para analisar as lutas concretas, tanto as que exigem respostas econômicas quanto as culturais-valorativas.

Aberto o campo de discussão, o recorte territorial do texto reside nos espaços públicos na conjunção entre a Av. Paulista e o Museu de Arte de São Paulo. A autora retoma o período em que ali se configurava o "centro novo", feito de casarões, mas desenvolve sobretudo a análise do momento recente, quando o Terraço Trianon se torna o "vão do MASP", palco de intervenções numerosas. 0 projeto de Lina se torna ali catalisador de uma cultura urbana densa e participativa - o que atualmente, vale lembrar, oscila entre elementos promissores e outros regressivos. O MASP é, podemos dizer, um exemplo muito feliz, no qual a arquitetura cumpre seus propósitos mais amplos. Temse a ampliação do que é púbico em termos físicos - pela proposta de elevá-lo por completo - e simbólicos; uma expansão do sensível partilhado como comum. Além disso, um lugar de ativação da vida urbana feita de heterogeneidade, de conflitos e de encontros.

No terceiro bloco Pallamin analisa uma série de iniciativas poético-políticas mobilizadas por esta combinação entre inventividade e valorações contrahegemônicas. Muitas delas realizadas por coletivos artísticos, cuja multiplicação é significativa nos anos 1990 e 2000. A autora analisa experimentações da Frente Três de Fevereiro junto ao Movimento Sem Teto do Centro (MSTC), nas reconfigurações do espaço simbólico da Ocupação Prestes Maia. Trata também da construção de uma espacialidade multiescalar em 0 Céu nos Observa, uma iniciativa convocada pelas redes, na qual uma série de intervenções ocorrem simultaneamente, vividas na dimensão local e, ao mesmo tempo, transmitidas e mapeadas via satélite em escala metropolitana. Mas talvez a mais potente destas experimentações seja a história a contrapelo montada em Bom Retiro 958 metros, peça realizada pelo Teatro da Vertigem em 2012. Nesta se entrelaçam ação artística site specific e intervenção urbana. Encenação e teatro espontâneo das ruas convergem para uma temporalidade crítica e intensificada.

Pallamin está ciente de que, em todas estas reaproximações entre arte e cidade, estão questões já antigas da relação entre as artes e a expectativa de changer la vie. Entre estas, talvez uma das mais recorrentes seja aquela que envolve os riscos da arte espraiar-se na literalidade - quando a transfiguração que Ihe é própria cede lugar a um realismo colado nos códigos circulantes pela indústria cultural ou pela realpolitik. Questões espinhosas, passíveis de avaliação apenas a posteriori, caso a caso e no interior da trajetória de seus agentes.

O texto de Vera Pallamin é muito providencial, não somente porque traz elementos fundamentais para os círculos de debates ligados aos estudos urbanos e à estética materialista, por meio de novas mediações entre autores 
da Teoria Crítica e as práticas urbanas. Mas é oportuno também para ampliar o repertório de ação de uma série de agentes coletivos que vem retomando com forte teor de irreverência e ludicidade o uso das ruas, em embates que visam ora legitimar demandas - por meio de visibilidade pública -, ora exigir participação em decisões coletivas, ora experimentar formas de sociabilidade mais inventivas e horizontais e, ainda, proclamar valorações não-hegemônicas.

Ousemos dizer que, a despeito de gritantes regressões na política institucional em nível federal, um caldo de cultura urbana se constituiu nos últimos densos três anos por meio de uma injeção de libido coletiva em diversos espaços que, com isto, inscreveram-se no imaginário social como inflexões e marcos locais. Não custa lembrar da heterotopia efervescente do \#OcupeEstelita. Do crescimento exponencial da bicicultura, legitimada e em grande medida alavancada pelo poder público municipal de São Paulo. Vale mencionar também o protagonismo de movimentos de moradia na aprovação do Plano Diretor e na visibilização das irracionalidades do urbanismo de megaeventos nas periferias do globo, um empoderamento verificado pelo aumento no número de ocupações - de 250 ocupações em 2011-2012 para algo em torno de 680 em 2013-2014 - e, ainda, por regularizações de ocupações paradigmáticas como a Prestes Maia, tratada inclusive no livro de Pallamin. Não menos importante são os agenciamentos abertos pelos urbanismos bottom up e, ainda, as ações múltiplas dos secundaristas em defesa da educação pública, começando por ocupar escolas, passando pelo bloqueio de avenidas até um acampamento pleno de verve no interior da Assembleia Legislativa do Estado de São Paulo. Todos estes espaços, alguns temporários, outros mais permanentes, foram experiências sociais de grande intensidade para grupos e atores que ainda estão entrando em cena, cujos papeis futuros ainda não sabemos quais serão.

\section{Paolo Colosso}

Doutorando em Filosofia na Faculdade de Filosofia, Letras e Ciências Humanas da Universidade de São Paulo

CV: http://lattes.cnpq.br/5525622524384542

paolocolosso@gmail.com 